\title{
Hybrid management of perforated gangrenous gallbladder
}

A 72-year-old man, with a history of myelodysplastic syndrome with chemotherapy and previous choledocholithiasis treated by endoscopic extraction, presented with acute cholecystitis. Because of his co-morbidities, he was not a candidate for surgery. Therefore, he underwent successful endoscopic ultrasound (EUS)-guided transduodenal gallbladder

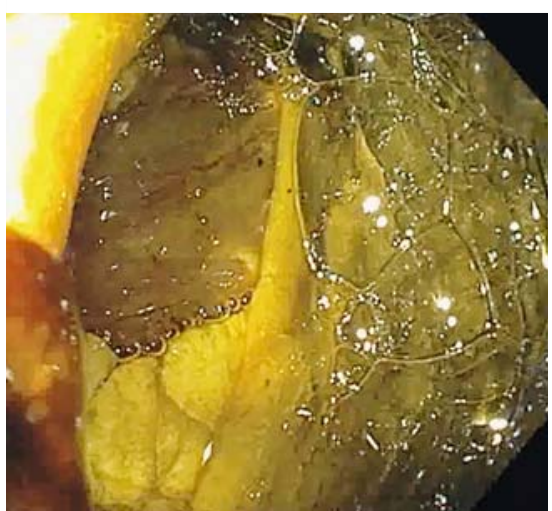

- Fig. 1 A moderate-size defect within the gallbladder cavity in a 72-year-old man with co-morbidities who had undergone successful endoscopic ultrasound (EUS)-guided transduodenal gallbladder drainage using a lumen-apposing metal stent (LAMS). drainage using a lumen-apposing metal stent (LAMS). The patient's clinical status worsened, with peritoneal signs 2 days later. Abdominal computed tomography $(C T)$ was done which showed the LAMS in place, and a possibly perforated gangrenous gallbladder.

After discussion with the surgical team, the decision was made to perform an emergent laparoscopic cholecystectomy. However, to facilitate the cholecystectomy, the cholecystoduodenal fistula ideally needed to be closed endoscopically.

During upper endoscopy, the endoscope was advanced into the duodenal bulb, through the previously placed LAMS, and into the gallbladder cavity ( Video $\mathbf{1}$ ). After suctioning of bile and removal of numerous gallstones, a moderate-size defect was visualized within the gallbladder wall (> Fig.1). Under fluoroscopic guidance, the endoscope was advanced into the peritoneum. Large-volume peritoneal lavage was performed. Following this, the LAMS was removed endoscopically, and the duodenal defect was successfully closed with an over-the-scope clip.

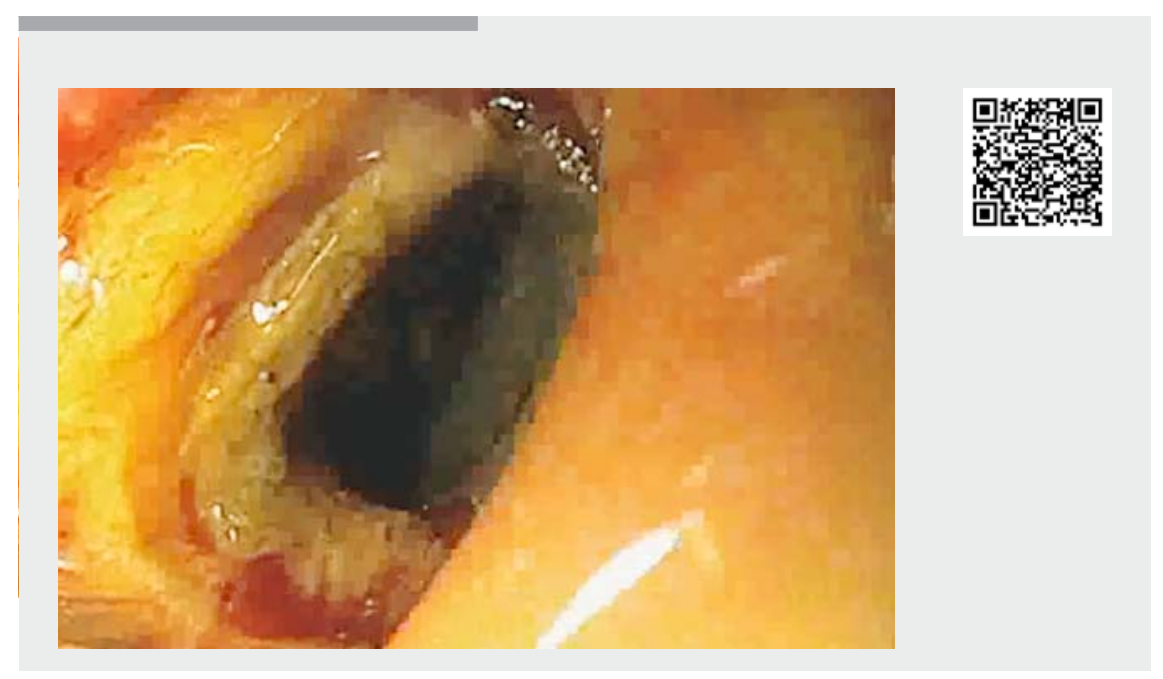

Video 1 A combined endoscopic and surgical approach for delayed perforation gangrenous gallbladder.
Subsequently, the patient underwent an emergent laparoscopic cholecystectomy ( $\triangleright$ Video 1). During the surgery, the gallbladder wall appeared to be gangrenous. A successful laparoscopic cholecystectomy was performed with no evidence of the duodenal defect during surgery; therefore, primary closure of the duodenum was not necessary. The patient was discharged in good clinical condition 8 days after the cholecystectomy.

EUS-guided gallbladder drainage has been shown to be a safe and efficacious approach for gallbladder drainage [1,2]. However, the usage of LAMS should be avoided in the gangrenous gallbladder. Transduodenal gallbladder drainage may make laparoscopic cholecystectomy difficult in patients who subsequently become a surgical candidate. This case demonstrates successful management of a delayed perforated gangrenous gallbladder with a combined endoscopic and surgical approach.

Endoscopy_UCTN_Code_CPL_1AM_2AZ

Competing interests

Amy Tyberg has done consulting work for NinePoint Medical, EndoGastric Solutions, and Obalon Therapeutics. She is a director at Therapeutic Endoscopic Ultrasound Society. Michel Kahaleh has done consulting work for Boston Scientific, Interscope Med, and Abbvie. He has received research grants from Boston Scientific, Emcision, Conmed, Pinnacle, Cook, Gore, Merit, and Olympus. He is the CEO and Founder of Innovative Digestive Health Education \& Research Inc, Therapeutic Endoscopic Ultrasound Society and Obesity Coalition Inc. He is the CEO and Co-Founder of Clinical Research Directory Inc.

Avik Sarkar has done consulting work for US Endoscopy and Obalon Therapeutics. He is a director at Innovative Digestive Health Education \& Research Inc.

Haroon Shahid has done consulting work for US Endoscopy. 
Iman Andalib ${ }^{1}$, Daniel Kats ${ }^{1}$, Amy Tyberg ${ }^{1}$, Haroon Shahid' ${ }^{1}$, Susannah S. Wise ${ }^{2}$, Avik Sarkar ${ }^{1}$, Michel Kahaleh ${ }^{1}$

1 Department of Gastroenterology \& Hepatology, Rutgers Robert Wood Johnson, New Brunswick, New Jersey, USA

2 Department of Surgery, Rutgers Robert Wood Johnson, New Brunswick, New Jersey, USA

\section{Corresponding author}

Iman Andalib, MD

Division of Gastroenterology \& Hepatology, Rutgers Robert Wood Johnson, New Brunswick, NJ 08901

Fax: +1-732-235-7792

imanandalib@gmail.com
[1] Widmer ], Alvarez P, Sharaiha RZ et al. Endoscopic gallbladder drainage for acute cholecystitis. Clin Endosc 2015; 48: 411 420

[2] Walter D, Teoh AY, Itoi T et al. EUS-guided gall bladder drainage with a lumen-apposing metal stent: a prospective long-term evaluation. Gut 2016; 65: 6-8

\section{Bibliography}

DOI https://doi.org/10.1055/a-0929-3218

Published online: 1.7.2019

Endoscopy 2019; 51: E370-E371

(c) Georg Thieme Verlag KG

Stuttgart · New York

ISSN 0013-726X
ENDOSCOPY E-VIDEOS

https:|/eref.thieme.de/e-videos

口回 Endoscopy E-Videos is a free access online section, reporting 田: on interesting cases and new techniques in gastroenterological endoscopy. All papers include a high quality video and all contributions are freely accessible online.

This section has its own submission website at

https://mc.manuscriptcentral.com/e-videos 